\title{
Reviews
}

\section{Mortality and survival in Type 2 (non-insulin-dependent) diabetes mellitus}

\author{
G. Panzram \\ Outpatient Department of Internal Medicine, Medical Academy, Erfurt, German Democratic Republic
}

The prognosis of a patient with Type 2 (non-insulin-dependent) diabetes mellitus varies considerably from one individual to another. The reasons for the variability in the individual prognoses include (1) the possibility that Type 2 diabetes in a given patient represents a clinically inconsequential metabolic disorder without any sequelae for length and quality of life; (2) the occurrence of severe, life-shortening vascular complications in association with Type 2 diabetes; and (3) the development of acute life-threatening events such as (hyperosomolar or ketoacidotic) coma or iatrogenic complications, e.g. hypoglycaemia. As with other chronic diseases, generalisations of the prognoses of Type 2 diabetes by means of mortality and survival statistics are of limited predictive value for individual outcomes. However, knowledge about its course and natural history characterises the impact of the disease on public health, thus forming an essential basis for improved prevention and therapy strategies.

\section{Methodological problems in assessing mortality}

Epidemiological analyses of prognoses of Type 2 diabetes are difficult to interpret, due to both inter-individual variations and considerable methodological problems. Therefore, before reviewing results of recent studies concerning mortality and survival in Type 2 diabetes, it appears necessary to briefly highlight the most important critical points of view; no attempt will be made, however, to give a comprehensive survey of this ambiguous subject.

Apart from a few recent reports [1, 2], mortality statistics related to non-insulin-dependent diabetes have been based on study populations in which no distinction has been made between both major types of the disease. In general, the clear-cut classification of Type 1 (insulin-dependent) and Type 2 (non-insulin-dependent) diabetes still constitutes an unsolved problem [3, 4], which is all the more evident in retrospective evaluations. Therefore, in most studies dealing with mortality in Type 2 diabetes, patients were classified according to the onset of the disease (e. g. beyond the age of 30,40 or 45 , respectively) with the assumption that the vast majority of non-insulin-dependent diabetic patients could be identified [5-9]. Age at onset and method of treatment are somewhat arbitrary criteria for classification of diabetic patients into those with Type 1 and Type 2 diabetes $[3,10,11]$. However, when reviewing mortality statistics from investigations performed before the introduction of the current WHO classification, there is no other way to evaluate available data. The notorious lack of reliability and validity of death certificates represents a further major problem concerning mortality statistics. In most countries, mortality records are distorted by under-reporting diabetes either as the underlying or contributory cause of death [12-16]. According to a recent review [6], the proportion of death certificates for diabetic individuals, not even coding for "diabetes", varies from $25 \%$ to $77 \%$. In Type 2 diabetes the probability of non-coding diabetes increases in the light of the age-related development of multi-morbidity $[8,17]$. On the other hand, it must be taken into account that the calculation of life expectancy is influenced by the extent of under-reporting in death certificates $[15,18,19]$. Mortality statistics on diabetes are frequently biased by unavoidable and unknown selection factors. This limitation applies not only to the bias inherent in analyses of life insurance data, but also to cross-sectionally performed regional mortality studies and investigations carried out at prestigious diabetes centres. Statistics derived from analyses of hospital and clinic populations have proven to be particularly error-prone due to inevitable referral bias $[20,21]$. The most reliable results can be expected from prospective studies of defined cohorts recruited from general population surveys. However, some of those frequently quoted population-based investigations include only a rather small number of longitudinally observed patients, e.g. in Evans County [22], Bedford [23] or Framingham [24].

Finally, whether the Type 2 diabetes of today will experience the same prognosis in the future as presently 
Table 1. All-cause excess mortality in study populations consisting predominantly or exclusively of Type 2 (non-insulin-dependent) diabetic patients

\begin{tabular}{|c|c|c|c|c|c|c|}
\hline Author [reference number] & Year & Region & $\begin{array}{l}\text { Age at } \\
\text { diagnosis }\end{array}$ & \multicolumn{3}{|c|}{ Excess mortality } \\
\hline Goodkin [25] & 1975 & USA & $\begin{array}{l}40-49 \\
50-59 \\
60+\end{array}$ & & & $\begin{array}{l}3.01 \\
2.13 \\
2.34\end{array}$ \\
\hline Krolewski et al. [26] & 1977 & Warsaw & $\begin{array}{l}30-49 \\
50-68\end{array}$ & $\begin{array}{l}2.13 \\
1.17\end{array}$ & $\begin{array}{l}1.61 \\
1.22\end{array}$ & \\
\hline Panzram and Zabel-Langhennig [27] & 1981 & Erfurt & $\begin{array}{l}40-49 \\
50-59 \\
60-69 \\
70-79\end{array}$ & $\begin{array}{l}1.80 \\
1.47 \\
1.40 \\
1.09\end{array}$ & $\begin{array}{l}1.86 \\
1.81 \\
1.37 \\
1.15\end{array}$ & \\
\hline Barrett-Connor and Wingard [28] & 1983 & California & $40-79$ & 1.5 & 2.3 & \\
\hline Zwaag et al. [16] & 1983 & $\begin{array}{l}\text { Atlanta } \\
\text { Memphis }\end{array}$ & $\begin{array}{l}45-54^{\mathrm{c}} \\
55-64 \\
65-74 \\
75+\end{array}$ & & & $\begin{array}{l}2.07 \\
1.57 \\
1.26 \\
1.07\end{array}$ \\
\hline Jarrett [29] & 1985 & Whitehall & Type 2 & 2.38 & & \\
\hline
\end{tabular}

a Treatment with diet only; ${ }^{b}$ treatment with oral drugs; ${ }^{c}$ age at cohort-entry

observed and retrospectively analyzed must be questioned for several reasons. Due to the changing diagnostic criteria of overt diabetes during the last several decades, former mortality and survival statistics cannot be considered representative of present study populations of non-insulin-dependent diabetic patients defined by the current WHO criteria. Thus, most of the longitudinal and cross-sectional mortality studies on diabetic populations initiated in the sixties and seventies have included a considerable percentage of patients with "chemical" or "subclinical" diabetes - today labelled as "impaired glucose tolerance" and usually not considered a facet of Type 2 diabetes.

All these shortcomings and fallacies in mortality statistics of Type 2 diabetes must be kept in mind, and require in principle a very cautious interpretation of the data published in this regard.

\section{All-cause excess mortality}

The results of all-cause mortality analyses on study populations consisting predominantly or exclusively of patients with non-insulin-dependent diabetes are listed in Table 1. Besides two studies [26, 27], all investigations tabulated were performed prospectively with follow-up periods ranging from 7 to 20 years. The excess mortality risk in these studies was evaluated against age- and sexrelated segments of the general population using var- ious statistical methods. Notwithstanding the great variations in data collection and study design, the data summarized in Table 1 justify the following general conclusions:

1) Age- and sex-related overall mortality rates of patients with Type 2 (non-insulin-dependent) diabetes are approximately twice as high as those of non-diabetic individuals. There are only relatively small inter-study differences in mortality risk between the findings of investigations in different countries and at different times. The rather consistent pattern of excess mortality appears surprising, particularly since the duration of prospective observation periods varies widely.

2) Mortality in Type 2 diabetes is characterised by a similar pattern for both sexes. All studies correspond insofar as the overall mortality rates in female Type 2 diabetic patients exceed or equal those in males. The loss of the favourable status of women characteristic of the general population regarding their life expectancy emphasizes the relatively greater impact of Type 2 diabetes as a mortality risk in females than in males.

3) Type 2 diabetes is associated with an increased mortality at all ages. However, the difference in death rates in comparison to those of the general population narrows remarkably with advancing age. As shown in Table 1, the degree of excess mortality declines consistently with increasing age at diabetes onset in all 
Table 2. Age-related reduction of life expectancy (mean of years lost) in diabetic patients

\begin{tabular}{llll}
\hline $\begin{array}{l}\text { Age }^{\mathrm{a}} \\
\text { (years) }\end{array}$ & $\begin{array}{l}\text { Marks and } \\
\text { KralI }^{\mathrm{b}} \\
1971[32]\end{array}$ & $\begin{array}{l}\text { Goodkin } \\
1975[25]\end{array}$ & $\begin{array}{l}\text { Panzram and } \\
\text { Zabel- } \\
\text { Langhennig } \\
\text { 1981 [27] }\end{array}$ \\
\hline $10 /<15$ & $(17)$ & 27 & - \\
$15-19$ & $16-17$ & 23 & - \\
$20-29$ & $12-14$ & 16 & - \\
$30-39$ & $10-11$ & 11 & - \\
$40-49$ & $8-9$ & 10 & $7-8$ \\
$50-59$ & $6-7$ & 6 & $5-6$ \\
$60-69(70)$ & $4-5$ & 5 & $3-4$ \\
$70+$ & - & - & 3 \\
\hline
\end{tabular}

a Age identified as age at onset [25,27] or attained age in decimal numbers [32]; ${ }^{\mathrm{b}}$ calculated and rounded from given data

studies. Our own representative 10 year cohort study within the closed diabetic population of the Erfurt district did not demonstrate any significant differences in the death rates of Type 2 diabetic patients beyond the age of 75 years as compared to non-diabetic control subjects [27].

\section{Reduction of life expectancy}

The question as to what extent Type 2 diabetes shortens life can be answered only with reservation. According to the recent Report of the WHO Expert Committee (1985), the life expectancy of non-insulin-dependent diabetic patients can either be normal or, on the average, reduced by "several years" [30]. For various reasons, there are only few reliable data but many rough estimates. Due to the rather different prognoses of Type 1 and Type 2 diabetes, failure to distinguish between them, or misclassification within study populations, must be considered as particular sources of inaccuracy.

Statistical evaluations correspond insofar as the difference in length of life compared with the age- and sexmatched segments of the general population depends on the age at onset $[7,8,12,15,18,31]$. For patients with non-insulin-dependent diabetes, as well as for those with insulin-dependent diabetes, the reduction in life expectancy declines continuously with increasing age at diagnosis. The data in Table 2 illustrate the results of three studies $[25,27,32]$, expressed in terms of years lost. Despite great differences in the selection of the study populations and in overall study design, the number of lost years is quite similar in the patients with diabetes onset beyond the fourth decade of their lives, most of whom supposedly had Type 2 diabetes. Taken together, it appears justified to assume that the reduction in life expectancy of middle-aged patients with Type 2 diabetes amounts to 5-10 years on the average. In some studies the impact of non-insulin-dependent diabetes on survival proved to be even more pronounced, as has been demonstrated by the prospective 29-year case-control analysis in Oxford, Massachusetts, which showed a diminished survival time of $10-15$ years in females and 6-9 years in males, respectively [33].

On the other hand, Type 2 diabetes with onset in the elderly has little or no effect on longevity $[8,18,34]$. Our own prognostic investigation in the diabetic population of the Erfurt district demonstrated no differences in life expectancy of non-insulin-dependent diabetic patients aged over 75 years [27, 35]. Similar observations have previously been reported from Birmingham [36]. Recently, reanalyses of the data of the Natural History Study from the Joslin Clinic provided nearly identical median survival times for diabetic patients diagnosed after age 70 as compared to the general population [7].

In accordance with the data on excess mortality, the survival pattern in Type 2 diabetes is found to be quite similar for both sexes [7, 12, 27]. Few studies suggest a particularly unfavourable prognosis for women [33], especially in middle age $[13,17,26]$. In any case, since females in the total population survive longer than males, the lack of any (or even an inverted) sex difference of reduction in life expectancy confirms the relatively greater prognostic impact of Type 2 diabetes in women.

\section{Cause of death}

Reliable "cause-of-death" statistics are hardly available, particularly due to the limitations of prognostic studies in Type 2 diabetes. It must be considered a major problem that nearly all studies fail to differentiate between the two main types of diabetes. The grouping of patients according to treatment and age at onset is frequently used for a retrospective arbitrary classification into Type 1 and Type 2 diabetes. Numerous recently reviewed [37-40] clinical and epidemiological investigations, including prospective studies in unselected population-based surveys, provide unequivocal evidence for cardiovascular and cerebrovascular diseases as the leading causes of mortality in Type 2 diabetes.

Particular reliability must be ascribed to cause-ofdeath statistics emerging from geographically defined and systematically registered diabetic populations, i.e. those not distorted by under-reporting or selection bias and, in the vast majority, consisting of patients with non-insulin-dependent diabetes. The findings of such a valid epidemiological study of mortality rates based on a continuous and complete control register are shown in Table 3, which includes all 1694 diabetic patients deceased over an 11-year period in the Erfurt City district [41].

The data demonstrate that arterial disease accounts for approximately $50-60 \%$ of all deaths within this closed diabetic population. This finding corresponds to the frequency of deaths due to macroangiopathy found in two other population-based studies in Rochester, Minnesota [12, 14] at various time periods (1945-1970, 
Table 3. Distribution (\%) of causes of death in all deceased patients of the closed and centrally registered diabetic population of the Erfurt City district, $1960-1970^{\mathrm{a}}$

\begin{tabular}{|c|c|c|c|c|c|}
\hline & $\begin{array}{l}\text { Ambulatory } \\
\text { diagnosis } \\
n=961\end{array}$ & $\begin{array}{l}\text { Clinical } \\
\text { diagnosis } \\
n=362\end{array}$ & $\begin{array}{l}\text { Diagnosis } \\
\text { by autopsy } \\
n=371\end{array}$ & $\begin{array}{l}\text { Total }^{\mathrm{b}} \\
n=1694\end{array}$ & \\
\hline Vascular disease & 66.0 & 55.2 & 46.4 & & 59.4 \\
\hline Coronary heart disease & 38.9 & 30.9 & 27.5 & 34.7 & \\
\hline Cerebrovascular disease & 25.6 & 20.4 & 14.1 & 22.0 & \\
\hline $\begin{array}{l}\text { General atherosclerosis } \\
\text { including gangrene }\end{array}$ & 1.5 & 3.9 & 4.8 & 2.7 & \\
\hline Infections & 5.2 & 8.3 & 9.2 & & 6.7 \\
\hline Tuberculosis & 0.6 & 1.1 & 1.3 & & 0.9 \\
\hline Malignant neoplasm & 8.8 & 8.6 & 14.3 & & 10.0 \\
\hline Accident/Suicide & 2.2 & 2.5 & 1.6 & & 2.1 \\
\hline Other causes & 9.4 & 13.8 & 14.6 & & 11.4 \\
\hline Unknown & 5.5 & 1.1 & 0.3 & & 3.4 \\
\hline
\end{tabular}

a Modified from Panzram et al. [41]; ${ }^{b}$ among 1694 deceased diabetic patients, age at diagnosis below 40 years in $2.1 \%$

Table 4. Prospective population-based studies on coronary heart disease mortality risk in predominantly middle-aged diabetic patients

\begin{tabular}{|c|c|c|c|c|c|}
\hline \multirow[t]{2}{*}{ Study location } & \multirow[t]{2}{*}{ Year } & \multirow{2}{*}{$\begin{array}{l}\text { Age } \\
\text { (years) }\end{array}$} & \multirow{2}{*}{$\begin{array}{l}\text { Follow-up } \\
\text { (years) }\end{array}$} & \multicolumn{2}{|c|}{ Mortality risk ratio ${ }^{a}$} \\
\hline & & & & Males & Females \\
\hline $\begin{array}{l}\text { DuPont } \\
\text { Company [42] }\end{array}$ & 1970 & $<20-64^{e}$ & 10 & $2.87^{b, d}$ & \\
\hline Israel [43] & 1977 & $\geq 40$ & 5 & $3.4^{\mathrm{b}, \mathrm{d}}$ & \\
\hline Framingham [44] & 1979 & $45-74$ & 20 & 1.7 & $3.3^{c}$ \\
\hline $\begin{array}{l}\text { Evans } \\
\text { County [22] }\end{array}$ & 1980 & & 4.5 & 1.0 & $2.8^{\mathrm{b}}$ \\
\hline $\begin{array}{l}\text { Rancho } \\
\text { Bernardo [28] }\end{array}$ & 1983 & $40-79$ & 7 & 2.4 & $3.5^{\mathrm{c}}$ \\
\hline Warsaw [34] & 1984 & $18-68$ & 9.5 & 1.33 & $1.65^{\mathrm{b}}$ \\
\hline Whitehall [45] & 1985 & $40-64$ & 10 & $2.45^{\mathrm{c}}$ & \\
\hline Chicago [46] & 1986 & $35-64$ & 9 & 3.8 & $4.7^{\mathrm{c}}$ \\
\hline Finland [47] & 1986 & $40-69$ & 11 & 2.0 & $4.1^{\mathrm{b}, \mathrm{d}}$ \\
\hline
\end{tabular}

a Rancho Bernardo and Warsaw identified ischaemic heart disease; Israel identified myocardial infarction; all others identified coronary heart disease; ${ }^{b}$ relative risk (observed/expected death proportion, standardized mortality ratio) Evans County and DuPont Company not age-adjusted; all others age-adjusted; ${ }^{c}$ multiply-adjusted risk including age and major coronary heart diesease risk factors with interstudy variations in covariates and statistical methods; ${ }^{\mathrm{d}}$ newly diagnosed diabetic patients; ${ }^{e}$ among a total of 370 diabetic patients, only 9 patients aged below 40 years

$54 \% ; 1965-1974,49 \%)$. In a prospective study of patients with Type 2 diabetes in Finland, Reunanen [1] observed a more frequent occurrence of deaths from cardiovascular disease (males, $72 \%$; females, 69\%). In a comprehensive world-wide review, Pyorälä and Laakso [38] considered macroangiopathy to be the cause of death in $70-75 \%$ of diabetic patients deceased in middle age or later.

Table 3 illustrates, however, that the distribution of causes of death depends to a certain extent on different degrees of diagnostic reliability, e. g. whether the diagnoses were established in an outpatient setting, in a hospital or by autopsy. Undoubtedly the incidence of car- diovascular and cerebrovascular events is overestimated in deceased outpatients, since sufficient diagnostic information for correct coding of cause of death is often not available [13].

Coronary heart disease represents the most prominent cause of death in Type 2 diabetes. Prospective population-based studies in middle-aged diabetic patients, most of whom apparently have Type 2 diabetes, are summarized in Table 4. The age-adjusted cause-specific mortality rate for coronary heart disease proved to be 2-4 times higher in diabetic patients than in comparable non-diabetic control subjects. Furthermore, a relatively greater excess risk for females appears evident. However, in some studies the frequency of fatal coronary events was found to be equal in both sexes $[26,27,48]$. The coronary excess risk is due to a higher incidence of myocardial infarction $[6,12,24,26,43,49,50]$, as well as an increased acute case fatality $[7,51,52]$ and a more unfavourable long-term prognosis [9, 37, 53]. Besides coronary events, there is strong evidence that congestive heart failure without significant atherosclerosis occurs more frequently in diabetic patients than in the general population $[28,38,47]$.

The second major cause of death in Type 2 diabetes is cerebrovascular disease, with a close relationship to the frequently co-existing hypertension. According to the most recent Report of the WHO Committee [30], stroke accounts for $15 \%$ of all deaths in non-insulin-dependent diabetic patients. However, there are only few prospective and representative studies concerning incidence and prevalence of stroke in diabetic patients [29, 47]. The data published to date justify the conclusion that approximately a 2- to 4-fold higher excess risk exists in both sexes for death from cerebrovascular disease in Type 2 diabetic patients than in respective nondiabetic individuals $[8,47,52,54-56]$. Only in a few studies was a more frequent occurrence of stroke found in females than in males $[12,54]$. On the other hand, in a 
Table 5. Prevalence of coronary risk factors (\%) in newly diagnosed Type 2 (non-insulin-dependent) diabetic patients of the Diabetes Intervention Study (DIS) compared with the age-adjusted general population of the Dresden Study ${ }^{\mathrm{a}}$

\begin{tabular}{|c|c|c|c|c|}
\hline Risk factor & $\begin{array}{l}\text { Type } 2 \text { diabetic patients } \\
(n=1139)\end{array}$ & $\begin{array}{l}\text { General population } \\
(n=1216)\end{array}$ & Limits & \\
\hline Hyperlipoproteinaemia (HLP) & 17.6 & 7.6 & & \\
\hline Hypercholesterolaemia & 3.5 & 3.7 & and/or & \\
\hline Mixed HLP & 2.8 & 0.5 & cholesterol & $\geq 7.76 \mathrm{mmol} / 1$ \\
\hline \multirow[t]{2}{*}{ Hyperuricaemia } & 22.5 & 3.8 & Males & $>416 \mu \mathrm{mol} / 1$ \\
\hline & & & Females & $>357 \mu \mathrm{mol} / 1$ \\
\hline
\end{tabular}

a Adapted from Hanefeld et al. [64, 65, 90]

large 12-year prospective study performed in Gothenburg, Sweden, an increased incidence of stroke in middle-aged diabetic women as compared to the general population could not be found [57]. In the oldest age groups of patients with Type 2 diabetes the mortality risk due to cerebrovascular events nears that of elderly people in the total population $[38,50]$.

There are few valid data about the development of nephropathy and the occurrence of renal death in Type 2 diabetes deriving from representative type-defined study populations. As far as can be judged at the present time, the frequency of death due to renal failure in non-insulin-dependent diabetic patients of Caucasian origin appears not to exceed $5 \%$. Thus, the proportion of death from renal disease found in populationbased mortality statistics amounts to $2.9 \%$ [41], 2.0\% [12] and $1.6 \%$ [14], respectively. The relative risk of renal mortality in Type 2 diabetes compared with that of ageadjusted non-diabetic control subjects seems to be only doubled [58], in apparent contrast to the prognostic impact of renal disease on Type 1 (insulin-dependent) diabetes. The cumulative mortality rates due to renal failure in patients of the Joslin Clinic, Boston, by age 75 were $7.4 \%$ in males and $7.6 \%$ in females [7]. Taken together, these data demonstrate that manifestations of microangiopathy are, at most, of minor importance for the prognosis of Type 2 diabetes, at least for Caucasians.

\section{Associated factors in mortality}

It would be beyond the scope of this review to discuss in detail the associations and inter-relationships of the major and minor risk factors for atherosclerosis in Type 2 diabetes. With regard to several recent reviews on this subject $[8,39,40,47,59]$, it appears justified to highlight the following general experiences as far as the excessmortality of Type 2 diabetes is concerned.

There exists conclusive evidence from a body of literature that the qualitative pattern of the major risk factors found in diabetes mellitus does not differ from that of the general population [29,60-63]. Quantitatively, the level of some risk factors for atherosclerosis appears to be increased in Type 2 diabetes [61, 62], as has been demonstrated in particular most recently by the Diabetes Intervention Study (DIS) in the GDR $[64,65]$. The baseline data of this large prospective multi-centre and multi-intervention trial, which includes 1139 unselected newly diagnosed patients with overt Type 2 diabetes aged 30-55 years, indicate an increased clustering of hypertension, hyperlipoproteinaemia and obesity in Type 2 patients as compared to the age-adjusted general population (Table 5). The cumulative incidence of the various risk factors is present in excess not only at the time of diagnosis [5,22,64,66,67], but also before overt diabetes has been established $[24,40,42,43,47,60]$.

The results obtained by using multivariate analyses in order to identify the most powerful risk predictor are not consistent, varying frequently from one study population to another. As in the general population, age must be regarded as a major determinant of mortality in Type 2 diabetes $[23,34,67]$. Beyond any doubt, furthermore, the mortality in non-insulin-dependent diabetic patients due to cardiovascular and cerebrovascular disease is markedly increased by co-existing hypertension $[68,69]$.

When adjusting the inter-related major risk factors of hypertension, hyper(dys)lipoproteinaemia, obesity and smoking by multiple logistic analyses, Type 2 diabetes itself appears to remain an independent contributor to arterial disease $[1,28,43,46,57,67]$. There are conflicting data, more of which deny [37, 62, 70-73] than claim $[25,42,51,74]$, that macroangiopathy is accelerated by the severity, i.e. the degree of long-term hyperglycaemia of Type 2 diabetes. However, it must be emphasized that the complex relationships between hyperglycaemia and the mutual interactions between the various established risk factors for the development of atherosclerosis are far from being understood, requiring much more study in order to clarify a multitude of unsolved problems. Whether the observed association between hypertension and hyperinsulinaemia can be considered a common link within the cluster of atherogenic risk factors [75-77] might be mentioned as one example of the many important open questions.

Nearly all investigations correspond insofar as the cause-specific cardiovascular excess mortality in Type 2 diabetes can be attributed only in part to the pattern and 
increased level of the recognized atherogenic risk factors $[24,29,47,52,55,61,62]$. Several prospective cohort approaches provide biostatistically conclusive evidence for the existence of yet unknown additional atherogenic conditions and mechanisms in Type 2 diabetes being responsible for the hitherto "unexplained" proportion of excess death rate. In this regard, it must be pointed out that, in principle, the impact of the risk factor concept for cardiovascular disease must be seen predominantly in terms of relative risk and not absolute risk [78].

Numerous investigations focusing on the hypothetical association of asymptomatic hyperglycaemia to cardiovascular mortality have provided inconsistent results $[38-40,47]$. The results of three prospective representative studies $[55,79-82]$ correspond insofar as univariate analyses suggest a non-linear relationship with a threshold-phenomenon in the upper range of the distribution of blood glucose values after an oral glucose load. In multivariate analyses, however, the association of blood glucose levels to cardiovascular disease appeared to be not independent from the other major risk variables. Taking into account the inconsistent, mainly negative, results of 14 longitudinal studies performed in nine countries and summarized within the International Collaborative Group [83], there is no definite proof for asymptomatic hyperglycaemia as being an independent risk factor for coronary heart disease.

In perplexing contrast to general knowledge of the development of microangiopathy and the course of macroangiopathy in Type 1 diabetes, duration of Type 2 diabetes has no influence on mortality risk due to arterial disease. There is overwhelming evidence for a high prevalence of already present atherosclerotic manifestations at the time of diagnosis in Type 2 diabetic patients, irrespective of their age at diagnosis $[5,9,50,62,63,67$, $72,73]$. In several studies comparing the death rates of previously and newly diagnosed diabetic patients, a quite similar cardiovascular mortality could be observed $[38,43,57]$.

Our own investigations in this regard, based on the geographically defined and, since 1956 , centrally registered diabetic population of the Erfurt district, yielded three key observations $[27,41,84]$ which underline and stimulate an alternative approach to the understanding of the relationship between atherosclerosis and Type 2 diabetes:

1) As outlined above (see Table 3 ), a complete registration of all 1694 diabetic patients deceased from 1960 to 1970 in the Erfurt district was performed. According to the well known age structure within such a closed and representative diabetic population, the vast majority of cases consisted of patients with non-insulin-dependent diabetes (age at diagnosis below age 40 only $2.1 \%$ ). Following an analysis of the distribution of time intervals between diagnosis and death [41], nearly half the patients $(45 \%)$ had died within 4 years after diagnosis. With regard to the relationship of Type 2 diabetes and athero- sclerosis, the high proportion of short-term diabetic patients among an unselected and bias-free study population of deceased patients appears of essential importance.

2) A prospective follow-up study of 250 diabetic patients detected by glucosuria screening in 1963 compared with properly pair-matched patients (by sex, age and weight) diagnosed spontaneously, yielded identical data on mortality, survival times and vascular complications after 10 years [84] and 20 years (unpublished observation).

3) In a 10-year longitudinal cohort study covering the entire population of 2560 diabetic patients of the Erfurt district newly diagnosed in 1966, an excess mortality was already evident in the first year after recruitment. The mortality rate in patients aged 40 years and older at diagnosis 10 years after entry into the study was equal to or even lower in some age groups than that observed during the first year of follow-up [27].

\section{Improvement of prognosis}

Whether conventional therapy in Type 2 diabetes has resulted in an improvement in prognosis is quite uncertain. Having in mind the complex multifactorial correlations in atherogenesis outlined above, it is not surprising that convincing evidence for a major beneficial effect is lacking $[17,37,54,85]$. In order to reliably study survival and mortality in chronic disease at different time periods, a comprehensive and suitable register of patients operative for a long time is required. The few studies fulfilling this prerequisite $[7,85,86]$ for populations consisting predominantly of Type 2 diabetic patients showed no (or only slight) prolongation of survival rates by the conventional treatment applied in the last several decades. The philosophy that early detection by mass screening and subsequent therapeutic intervention will be beneficial for the course of the disease and survival in non-insulin-dependent diabetes must be considered rather wishful thinking than a proven reality [84, 87-89]. Whether this experience will be confirmed by longitudinal studies of screened Type 2 diabetic patients defined by the present diagnostic criteria remains to be seen.

There are also conflicting data concerning recent national trends in diabetes mortality with reports of decreasing, unchanged, as well as increasing ratios [6]. These inconsistencies reflect a multitude of artefactual causes apart from the possibility of real changes in survival. A time-dependent alteration of the extent of under-reporting of diabetes in death certificates represents only one of the many artefacts leading to invalid conclusions from national mortality statistics. The complete centralized diabetes register of the GDR since 1960 offers the opportunity to gain unbiased prevalence and 
mortality data from a closed diabetic population. Due to this reliable epidemiological data base, the annual crude mortality rate of non-insulin-treated diabetic patients increased from $4.8 \%$ in 1961 to $7.0 \%$ in 1984 (Michaelis, personal communication).

\section{Concluding remarks}

All findings reviewed so far doubtlessly demonstrate that macroangiopathy in Type 2 diabetes cannot be categorized under the traditional umbrella of so-called "late complications". There is conclusive evidence that atherosclerosis and types of diabetes develop coincidentally, in parallel, or even in reversed sequence. It has been argued by Jarrett $[40,63]$ that Type 2 diabetes and hyperglycaemia might not be causally linked to a cardiovascular risk, but both conditions might be the consequence of a pre-existing, not yet identified, common genetic and/or metabolic basis. In fact, within the cluster of risk factors hyperglycaemia might much rather be a mere risk indicator [63] which unmasks a complex clinical syndrome of various interrelated genetic, metabolic and vascular constituents resulting in an overall atherogenic hazard [84]. Antecedent hypertension, hyper(dys)lipoproteinaemia and hyperinsulinaemia appear to be more strongly related to the atherosclerotic risk than hyperglycaemia. Therefore, we have previously hypothesized that a considerable number of those patients prone to develop Type 2 diabetes might not live long enough to manifest "their diabetes" because of the antedating occurrence of vascular end-points [41].

The future strategy against premature mortality in Type 2 diabetes requires multifactorial approaches. At present we are doing too little too late, if anything can be done at all. The potential improvement of prognosis in Type 2 diabetes calls for early and comprehensive measures against the entire complex of known metabolic and vascular risk factors, as well as progress in knowledge about additional (genetically determined) atherogenic conditions and mechanisms not yet identified.

\section{References}

1. Reunanen A (1983) Mortality in Type 2 diabetes. Ann Clin Res 15 [Suppl 37]: 26-28

2. Sasaki A, Uehara M, Hasagawa N (1983) A long-term follow-up study of Japanese diabetic patients: mortality and causes of death. Diabetologia 25: 309-312

3. Editorial (1985) Insulin-dependent? Lancet 4: 809-810

4. Keen H (1986) What's in a name? IDDM/NIDDM, Type1/ Type 2. Diabetic Med 3: 11-12

5. Janka HU (1985) Five-year incidence of major vascular complications in diabetes mellitus. Horm Metab Res [Suppl] 15: 15-19

6. Fuller JH (1985) Causes of death in diabetes mellitus. Horm Metab Res [Suppl] 15: 3-9

7. Królewski AS, Warram JH, Christlieb AR (1985) Onset, course, complications, and prognosis of diabetes mellitus. In: Marble A, Krall LP, Bradley RF, Christlieb AR, Soeldner J (eds) Joslin's diabetes mellitus, 12th edn. Lea and Febiger, Philadelphia, pp 251-275

8. Herman WH, Teutsch SM, Geis LS (1985) Closing the gap: the problem of diabetes mellitus in the United States. Diabetes Care $8: 391-406$

9. Pyörälä K (1985) Diabetes and coronary heart disease. Acta Endocrinol 110 [Suppl 272]: 11-19

10. Melton LJ, Palumbo PJ, Chu CP (1983) Incidence of diabetes mellitus by clinical type. Diabetes Care 6: 75-86

11. Laakso M, Pyörälä K (1985) Age of onset and type of diabetes. Diabetes Care 8: 114-117

12. Palumbo PJ, Elvebaak LR, Chu CP, Conolly DC, Kirkland LT (1976) Diabetes mellitus: incidence, prevalence, survivorship and causes of death in Rochester Minnesota 1945-1970. Diabetes 25: 566-573

13. Shenfield GM, Elton RA, Bhalla IP, Duncan LSP (1979) Diabetic mortality in Edinburgh. Diabete Metab 5: 149-158

14. Ochi JW, Melton LJ, Palumbo PJ, Chu CP (1985) A populationbased study of diabetes mortality. Diabetes Care 8: 224-229

15. Harris MI, Entmacher PS (1985) Mortality from diabetes. In: National diabetes data group. Diabetes in America, NIH Publication No 85-1468, US Govt Printing Office, pp XXIX/1-XXIX/48

16. Zwaag RV, Runyan JW, Davidson JK, Delcher HK, Mainzer I, Bagget HW (1983) A cohort study of mortality in two clinic populations of patients with diabetes mellitus. Diabetes Care 6: 341-346

17. Fuller JH, Elford J, Goldblatt P, Adelstein AM (1983) Diabetes mortality: new light on an underestimated public health problem. Diabetologia 24: 336-341

18. Bale GS, Entmacher PS (1977) Estimated life expectancy of diabetics. Diabetes 26: 434-438

19. Statistical Bull (1979) Life expectancy among diabetics in the United States. Jul-Sep, pp 6-8, Oct-Dec, pp 11-13

20. Melton LJ, Ochi JW, Palumbo PJ, Chu CP (1984) Referral bias in diabetes research. Diabetes Care 7:13-18

21. Bender AP, Sprafka JM, Jagger H, Wannamaker J, Muckala KH (1983) Incidence, prevalence, mortality and population-based profile of diabetes mellitus in Wadena, Minnesota, 1981. Minn Med 66: 251-256

22. Heyden S, Heiss G, Bartel G, Hames CG (1980) Sex differences in coronary mortality among diabetics in Evans County, Georgia. J Chronic Dis 33: 265-273

23. Jarrett RJ, McCartney P, Keen H (1982) The Bedford survey: ten year mortality rates in newly diagnosed diabetics, borderline diabetics and normoglycaemic controls and risk indices for coronary heart disease in borderline diabetics. Diabetologia 22: 79-84

24. Garcia MJ, McNamara PM, Gordon T, Kannell WB (1974) Morbidity and mortality in diabetics in the Framingham population. Diabetes 23: 105-111

25. Goodkin G (1975) Mortality factors in diabetes. J Occup Med 17: 716-721

26. Królewski AS, Czycźyk A, Janecźko D, Kopcźyński J (1977) Mortality from cardiovascular diseases among diabetics. Diabetologia 13: $345-350$

27. Panzram G, Zabel-Langhennig R (1981) Prognosis of diabetes mellitus in a geographically defined population. Diabetologia 20: 587-591

28. Barrett-Connor E, Wingard DL (1983) Sex differential in ischemic heart disease mortality in diabetics: a prospective populationbased study. Am J Epidemiol 118: 489-496

29. Jarrett RJ (1985) Risk factors of macrovascular disease in diabetes mellitus. Horm Metab Res [Suppl] 15:1-3

30. WHO Study Group on Diabetes Mellitus (1985) World Health Organization Tech Rep Ser 727, WHO, Geneva

31. Panzram G (1984) Epidemiologic data on excess mortality and life expectancy in insulin-dependent diabetes mellitus - critical review. Exp Clin Endocrinol 83: 93-100

32. Marks HH, Krall LP (1971) Onset, course, prognosis and mortality in diabetes mellitus. In: Marble $A$, White $P$, Bradley RF Krall LP (eds) Joslin's diabetes mellitus, 11th edn. Lea and Febiger, Philadelphia, pp 209-254

33. O'Sullivan JB, Mahan CM (1982) Mortality related to diabetes and blood glucose levels in a community study. Am J Epidemiol 116: 678-685 
34. Czycźyk A, Janecźko D, Kopczyński J, Królewski AS, Niewiadomska J, Karwanski M (1984) Prospective study of mortality among diabetics in Warsaw 1974-1983. Abstracts of the 19th Annual Meeting EDESG, pp 11-13

35. Zabel-Langhennig R, Panzram G (1981) Untersuchungen zur Prognose des Diabetes mellitus. Z Gesamte Inn Med 36: 411-416

36. Hayward RE, Lucena BL (1965) An investigation into the mortality of diabetics. J Inst Actuaries 91: 286-336

37. Fein FS, Scheuer J (1983) Heart disease in diabetes. In: Ellenberg $M$, Rifkin $H$ (eds) Diabetes mellitus, theory and practise. 3th edn, Medical Examination Publishing Co, New York, pp 851-861

38. Pyörälä K, Laakso M (1983) Macrovascular disease in diabetes mellitus. In: Mann YI, Pyörälä K, Teuscher A (eds) Diabetes in epidemiological perspective. Churchill, Livingstone, pp 183-247

39. Feingold KR, Siperstein MD (1986) Diabetic vascular disease. Adv Intern Med 31: 309-340

40. Jarrett RJ (1984) The epidemiology of coronary heart disease and related factors in the context of diabetes mellitus and impaired glucose tolerance. In: Jarrett RJ (ed) Diabetes and heart disease. Elsevier, Amsterdam, pp 1-23

41. Panzram G, Marx M, Frommhold E, Barthel R (1977) Untersuchungen über Sterbealter, erlebte Diabetesdauer und Todesursachen unter den Verstorbenen einer geschlossenen Diabetespopulation. Wien Klin Wochenschr 85: 147-150

42. Pell S, D'Alonzo CA (1970) Factors associated with long-term survival of diabetics. J Am Med Ass 214: 1833-1840

43. Herman JB, Medalie JH, Goldbourt U (1977) Differences in cardiovascular morbidity and mortality between previously known and newly diagnosed adult diabetics. Diabetologia 13:229-234

44. Kannel WB, McGee DL (1979) Diabetes and glucose tolerance as risk factors for cardiovascular disease: the Framingham study. Diabetes Care 2: 120-126

45. Jarrett RJ, Shipley MJ (1985) Mortality and associated risk factors in diabetics. Acta Endocrinol 110 [Suppl 272]: 21-26

46. Pan WH, Cedres LB, Liu K, Dyer A, Schoenberger JA, Shekelle RB, Stamler R, Smith D, Colette P, Stamler J (1986) Relationship of clinical diabetes and asymptomatic hyperglycemia to risk of coronary heart disease mortality in men and women. Am J Epidemiol 123: 504-516

47. Pyörälä K, Laakso M, Uusitupa M (1987) Diabetes and atherosclerosis: an epidemiologic view. Diabetes Metab Rev (in press)

48. Daisey RB, Arredondo A, Villalobos A, Lozano O, Guevara L, Kelly S (1984) Association of differing dietary, metabolic, and clinical risk factors with macrovascular complications of diabetes: a prevalence study of 503 Mexican Type II diabetic subjects. Diabetes Care 7: 421-427

49. Czycźyk A, Królewski AS, Szablowska S, Alot A, Kopczyúski J (1980) Clinical course of myocardial infarction among diabetic patients. Diabetes Care 3: 526-529

50. Aro A (1984) Macroangiopathy in type II diabetes. Acta Endocrinol [Suppl] 262: 75-78

51. Rytter LR, Troelsen S, Beck-Nielsen H (1985) Prevalence and mortality of acute myocardial infarctions in patients with diabetes. Diabetes Care $8: 230-234$

52. Jarrett RJ, Keen H, Chakrabarti R (1982) Diabetes, hyperglycaemia and arterial disease. In: Keen H, Jarrett RJ (eds) Complications of diabetes. 2nd edn. Edward Arnold, London, pp 179-203

53. Kannel WB (1981) Prospects for risk factor modification to reduce risk of reinfarction and premature death. $\mathrm{J}$ Cardiac Rehab 1: 63-71

54. Kannel WB, McGee DL (1979) Diabetes and cardiovascular disease. The Framingham Study. J Am Med Ass 241: 2035-2038

55. Fuller JH, Shipley MJ, Rose G, Jarrett RJ, Keen H (1983) Mortality from coronary heart disease and stroke in relation to degree of glycaemia: the Whitehall Study. Br Med J 287: 867-870

56. Kuller LH, Dorman JS, Wolf PA (1985) Cerebrovascular disease and diabetes. In: National diabetes data group. Diabetes in America. NIH Publication No 85-1468, US Govt Printing Office, pp XVIII/1-XVIII/18

57. Lapidus L, Bengtsson C, Blohmé G, Lindquist O, Nyström $\mathbf{E}$ (1985) Blood glucose, glucose tolerance and manifest diabetes in relation to cardiovascular disease and death in women. Acta Med Scand 218: 455-462

58. Geis LS, Herman WH, Teutsch SM (1985) Diabetes and renal mortality in the United States. Am J Publ Health 75:1325-1326

59. Laakso M (1986) Atherosclerotic vascular disease and its risk factors in non-insulin-dependent diabetics in East Finland. Publications of the University of Kuopio. Series Original Reports 6, pp 1-139

60. Kannel WB, McGee DL (1979) Diabetes and cardiovascular risk factors: the Framingham Study. Circulation 59: 8-13

61. Ganda OP (1983) Morbidity and mortality from diabetes mellitus: a look at preventable aspects. Am. J Publ Health 73: 1156-1158

62. Stout RW (1985) Hyperinsulinaemia - a possible risk factor for cardiovascular disease in diabetes mellitus. Horm Metab Res [Suppl] 15: 37-41

63. Jarrett RJ (1984) Type 2 (non-insulin-dependent) diabetes mellitus and coronary heart disease - chicken, egg or neither? Diabetologia 26: 99-102

64. Hanefeld M, Schulz J, Fischer S, Julius U, Dude H, Schmechel H, Klein S, Köhler K, Thiele P, Vater H-G, Rothe G, Haller H (1984) The diabetes intervention study (DIS): a multi-intervention trial in type II diabetes. In: Lenzi S, Descovich C (eds) Atherosclerosis and cardiovascular disease. MTP Press, Lancaster Boston, pp 83-103

65. Hanefeld M, Schulze J, Fischer S, Julius U, Schmechel H, Haller $H$ (1985) The diabetes intervention study (DIS): a cooperative multi-intervention trial with newly manifested type II diabetics: preliminary results. Monogr Atheroscler 13:98-103

66. Wingard DL, Barrett-Connor E, Criqui MH, Suarez L (1983) Clustering of heart disease risk factors in diabetics compared to nondiabetic adults. Am J Epidemiol 117: 19-26

67. Uusitupa M, Siitonen O, Pyörälä K, Aro A, Hersio K, Penttilä I, Voutilainen $\mathrm{E}$ (1985) The relationship of cardiovascular risk factors to the prevalence of coronary heart disease in newly diagnosed Type 2 (non-insulin-dependent) diabetes. Diabetologia 28 : 653-659

68. Fuller JH (1985) Epidemiology of hypertension associated with diabetes mellitus. Hypertension [Suppl II] 7:3-7

69. Janka HU, Dirschedl P (1985) Systolic blood pressure as a predictor for cardiovascular disease in diabetes. A 5-year longitudinal study. Hypertension [Suppl II] 7: 90-94

70. Pirart J (1978) Diabetes mellitus and its degenerative complications: a prospective study of 4400 patients observed between 1947 and 1973. Diabetes Care 1: 168-188, 252-263

71. Keen H (1978) Diabetes mellitus and heart disease. Isr J Med Sci 14: $413-417$

72. Nielsen NV, Ditzel J (1985) Prevalence of macro- and microvascular disease as related to glycosylated hemoglobin in Type I and II diabetic subjects. Horm Metab Res [Suppl] 15: 19-23

73. Barrett-Connor E, Orchard T (1985) Diabetes and heart disease. In: National diabetes data group. Diabetes in America, NIH Publication No 85-1468, US Govt Printing Office, pp XVI/1-XVI/41

74. Janecźko D, Czycźyk A, Kopczyński J, Krzyźanowski M (1986) Risk differentials of 10-year cardiovascular mortality among insulin-dependent and non-insulin-dependent diabetic patients. Diabetologia 29: 552 (Abstract)

75. Christlieb AK, Krolewski AS, Warram JH, Soeldner JS (1985) Is insulin the link between hypertension and obesity? Hypertension [Suppl II] 7: 54-57

76. Modan M, Halkin H, Almog S, Lusky A, Eshkol A, Shefi M, Shitrit A, Fuchs Z (1985) Hyperinsulinemia. A link between hypertension, obesity and glucose intolerance. J Clin Invest 75: 809-817

77. Singer $P(1986)$ Glukosestimulierte Hyperinsulinämie bei Frühstadien der essentiellen Hypertonie - ein unterschätzter biochemischer Risikoindikator. Z Klin Med 41: 1221-1226

78. Oliver MF (1986) Prevention of coronary heart disease - propaganda, promises, problems, and prospects. Circulation 73: 1-9

79. Fuller JH, Shipley MJ, Rose G, Jarrett RI, Keen H (1980) Coronary heart disease risk and impaired glucose tolerance: the Whitehall Study. Lancet 1: 1373-1376

80. Eschwege E, Richard JL, Thibult N, Ducimetière P, Warnet JM, 
Claude JR, Rosselin GE (1985) Diabetes, hyperglycaemia, hyperinsulinaemia and risk of coronary heart disease mortality. Data of the Paris Prospective Study, 10 years later. Rev Epidemiol Sante Publique 33: 352-357

81. Eschwege $E$, Richard JL, Thibult $N$, Ducimetière $P$, Warnet JM, Claude JR, Rosselin GE (1985) Coronary heart disease mortality in relation with diabetes, blood glucose and plasma insulin levels. The Paris Prospective Study, ten years later. Horm Metab Res [Suppl] 15: 41-46

82. Pyörälä K, Savolainen E, Kaukola S, Haapakoski J (1985) Plasma insulin as coronary heart disease risk factor: relationship to other risk factors and predictive value during $91 / 2$-year follow-up of the Helsinki Policemen Study population. Acta Med Scand [Suppl] $701: 38-52$

83. The International Collaborative Group (1979) Joint discussion on asymptomatic hyperglycemia and coronary heart disease. J Chronic Dis 32: 829-837

84. Panzram G, Ruttmann B (1978) Prognose des Diabetes mellitus nach Frühdiagnose durch Glucosurie-Screening. Schweiz Med Wochenschr 108: 221-225

85. Meyer H (1977) Zur Krankheitsprognose beim Diabetes mellitus. Z Gesamte Inn Med 77: 297-300

86. Warram JH, Marble A, Conlon TP (1982) Is cardiovascular mortality declining in diabetes? Diabetes 31 [Suppl 2]: 89 A (Abstract)
87. Bennett PH, Knowler WC (1984) Early detection and intervention in diabetes mellitus: is it effective? J Chronic Dis 8: 653-666

88. Manservigi D, Samori G, Graziani R, Bottoni L (1982) Impaired glucose tolerance and clinical diabetes: a 6-year follow-up of screened versus non-screened subjects. Diabetologia 23: 185 [Abstract]

89. Hawthorne VM, Cowie CC (1984) Some thoughts on early detection and intervention in diabetes mellitus. $J$ Chronic Dis 37 : 667-669

90. Hanefeld M, Haller H, Schulze J, Julius U, Fischer S, Rothe G (1984) Die Diabetesinterventionsstudie (DIS) - eine multizentrische Multiinterventionsstudie bei Typ II-Diabetikern. 1. Mitteilung: Konzeption, diagnostisch-therapeutisches Programm, Ergebnisse der Screeningphase und epidemiologische Befunde bei Eintritt in die Studie. Dtsch Gesundheitswes 39: 1889-1894

Received: 26 January 1987

Professor Dr. G. Panzram

Medizinische Poliklinik der Medizinischen Akademie Erfurt Nordhäuser Straße 84

DDR 5010 Erfurt

German Democratic Republic 